\title{
Eğitim Yönetiminin Özgünleşme ve Özerkleşme Sorunsalı
}

\author{
Hazal Takmak ${ }^{1}$
}

Öz

$\mathrm{Bu}$ çalışmanın amacı eğitim yönetimi alanının özgünleşme ve özerkleşmesini etkileyen etmenlerin irdelenmesidir. Bu amaç doğrultusunda alanın bilgi temelinde yaşanan gelişmelerin, alanın diğer alanlarla olan sınırlarının ve alanda yapılan çalıșmaların niteliğinin alanın özgünlüğünü ve özerkliğini nasıl etkilediği ortaya konmaya çalışılmıştır. Yapılan literatür taraması sonucunda, eğitim yönetimi alanın bilgi temelinin zaman içerisinde temelde pozitivist ve yorumsamacı olmak üzere çeşitli paradigmaların etkisi altında kalarak şekillenmeye başladığı ve buna bağlı olarak özellikle 1950'li yıllardan sonra alanın bilgi temeliyle ilgili çeşitli görüşlerin ortaya çıktığı görülmektedir. Alandaki bu görüşler alanın kendi özgün kimliğini kazanma çabaları olarak görülmektir. Ancak eğitim yönetimi alanının özellikle ișletme yönetimi alanın etkisi altında kaldığı ve alanın kendi sınırlarını belirleyememesine neden olduğu görülmektedir. Bu durumun ise alanın özerk bir kimlik kazanma yolundaki çabalarına ket vurduğu söylenebilir. Ayrıca alanda yapılan çalıșmaların, alandaki sorunları irdelemekten ziyade etkisi altında kalınan yaklaşımlar doğrultusunda yapıldığı ve tekrara düştüğü, bu nedenle de çalışmaların niteliğini etkilediği görülmektedir. Sonuç olarak alanın epistemolojik temelindeki çeșitliliklerin alanın özgünleşmesine katkı sunarken, yönetimin diğer alanlarıyla olan sınırlarının net olmaması, alanın özerkleşmesine engel teşkil etmekte; var olan bilim yapma anlayışına göre gerçekleşen çalışmalar ve akademisyenlerin akademik kaygıları alanı giderek özgünlükten ve özerklikten uzaklaştırmaktadır.

Anahtar Sözcülkler

Eğitim yönetimi Özgünleşme

Özerkleşme

Makale Hakkında

Gönderim Tarihi

13 Ağustos 2018

Kabul Tarihi

11 Şubat 2019

Makale Türü

Derleme

DOI: $10.12984 /$ egeefd.452705

The Originality and Autonomy Problem of Educational Administration

Abstract

Keywords

The aim of this study is to examine the factors that affect and prevent the original and autonomous identity development of the field. Based on this aim, the author tried to show how the developments on the knowledge basis of the field, the boundaries of the field with other fields and the nature of the studies in the field affect the originality and autonomy of the field. The existing literature indicated that the knowledge base of the field has begun to take shape under the influence of various paradigms and accordingly various views about the knowledge base of the field have emerged, especially after 1950 These views are seen as efforts to develop the field's own original identity. However, it seems that the field is particularly under the influence of business management. It causes the field to fail to create its boundaries. Studies in the field are repetitive. As a result, while the diversity of epistemological basis of the field contributes to the originality of the field, the lack of clarity of the boundaries constitutes an impediment to the automatization of the field. Also, the studies and the academic concerns of academicians move the field away from originality and autonomy.

Educational administration Originality Autonomy

Article Info

Received August 13, 2018 Accepted

February11, 2019

Article Type

Review

Atıf: Takmak, H. (2019). Eğitim yönetiminin özgünleşme ve özerkleşme sorunsalı. Ege Eğitim Dergisi, $20(1), 113-126$. doi:10.12984/egeefd.452705

\footnotetext{
1 (D) Hacettepe Üniversitesi, Eğitim Fakültesi, Eğitim Yönetimi Anabilim Dalı, Türkiye, hazaltakmak@gmail.com
} 


\section{Extended Abstract}

\section{Introduction}

As a scientific area, educational administration does not have a long history. Various scholars in educational administration try to come together at conventions, scientific journals are being published in the field, graduate programs at universities are opened, empirical and theoretical studies have gradually intensified in what might be called a relatively short period of time. There is no doubt that such developments are the kind of developments that will contribute to this scientific field to gain autonomy and become genuine. From this point of view, in this study, the factors that affect the originality and the autonomy of the field will be studied. Does a science field has its own unique character? Is the work done in the field original? To what degree it remains under the influence of other fields? Is it able to draw boundaries with other fields? And how independently can it act? Answers given to these questions will help us to determine to what extent the field of educational administration is an autonomous and an original branch of science. First of all, for a field of discipline to acquire an unique and autonomous identity; it is very important to determine the boundaries of the field. For determining the boundaries of the field, epistemological structure plays an important role. In order to understand a field's originality and autonomy, originality of the work in the field and institutionalization of the field is as much important as the clarity of its borders. Thus, in this research basis of the field, the boundaries of the field with other fields and the nature of the studies in the field are seen as the determinants of the originality and autonomy of the field.

\section{The Knowledge Basis of the Field}

Unlike other disciplines, the history of educational administration does not go back very far. Educational administration as a profession first appeared in the last quarter of the 19th century, and then started to develop among universities in the United States. At the beginning of the 20th century, the leading scientists in the area worked on efficiency and effectiveness. It seems that the knowledge base of the field was formed by using approaches and concepts specific to business management. In the early 20th century, after the opening of educational administration departments in the universities educational administration entered into a process of becoming an independent scientific field of study. After 1940s, several opinions related to the field's foundation of information began to emerge. In the 1950s, Theory movement that preserves the validity of scientific mentality today, become dominant and allowed the field to gain legality as a study area. In this period, education administration programs with graduate degrees were opened in various universities, mainly in the US and later in other Western countries, the researches gained volume and quality and studies started to be financed by the state institutions. In North America, Europe, Australia, and in various parts of the World various professional associations were founded in order to allow the exchange of intellectual and experimental field studies. Parallel to these developments, the first academic publications of the field began to appear. If Gulbenkian Report is taken in to consideration, it is possible to say that educational administration has become a scientific discipline as a result of the process of institutionalization that the field has been through. Although the administration theory benefited from general theoretical foundations of management, in the 1950s with the Theory movement, the field started to develop its distinctive theories and this theoretical development gained momentum especially after 1970s. Particularly though it seems to have been unsuccessful and criticized, starting with the theoretical movement, the introduction of different approaches to the field's foundations of knowledge that came from different academic circles suggests that educational administration has gained momentum in its efforts to gain its identity.

\section{The Boundaries of the Field}

The field of education administration has always been in an effort to create its own original identity. The main reason for failing to achieve this is that it cannot determine its boundaries with areas such as business management, public administration, and economics. According to Oplatka (2009), social and political forces have an impact on the separation of a scientific field from other fields and the determination of its boundaries. The field of education administration was influenced by the centralization and expansion trend observed in public administration until the 1980s. As a result of the liberal approach in the economy after 1980s, it is seen that the field is under the influence of some approaches such as total quality management, strategic management, which is transferred from the business administration, and it is concluded that the field cannot create its own autonomous identity. In fact, it seems inevitable that a field will be influenced by the existing understanding. However, the field is expected to develop theories and practices in line with its own needs and characteristics rather than to take the existing one directly. As a matter of fact, it is inevitable that education administration will be influenced by the liberal approach in the economy. Therefore the field should develop theories and practices in line with changing socio-economic, political and social paradigms considering the organizational structure and 
needs of the field. The field of education administration that has developed in this way can be thought to be a more autonomous scientific field.

Disciplines may be affected by the developments in related disciplines. As a result, sometimes interdisciplinary boundaries are not clearly defined. The epistemological structure of the discipline plays an important role in the determination of interdisciplinary boundaries (Donmoyer 2001; Klein, 1993). In the process, two types of thinking or paradigm dominate the field of education management, which are positivist and interpretive paradigm. It is observed that there are difficulties in producing theoretical knowledge in the field of educational administration. The reason for these difficulties is that there is no consensus on the knowledge base of the field. This is expressed by Özdemir (2017) as epistemic crisis, by Waite (2002) as paradigm war, and by Griffiths (1979) as intellectual confusion. However, the lack of consensus on the knowledge base of the field can be seen as the efforts of the field to gain an original identity.

\section{The Studies in the Field}

It is inevitable to think that the quality of the studies conducted in the field of educational administration will contribute to the originality of the field. From this token, several studies examining graduate theses and articles published in the area of educational administration in Turkey were examined. In the studies, it is seen that mostly similar subjects are studied, and generally quantitative methods are preferred. It would also not be wrong to say that the studies were conducted in the light of the prevailing paradigms. In addition, there is a gap or a distinction between theory and practice. The reasons for the gap between theory and practice are that the results of the studies are not shared, the studies are not oriented to the needs of the practitioners, the academicians do not take necessary and adequate initiatives, and the practitioners are not interested in scientific studies. However, considering the existing problems and avoiding repeating popular topics would suggest a link between theory and practice. Another reason that detracts the studies in the field to become original is scientists' academic concerns. To be an original and independent scientific field, the problems of education administration should be examined with the point of view of educational scientists, scholars in the field need to create a powerful community that will create its own norms, rules and standards and be able to impose those standards to their entourage. For this reason, rather than the efforts of the academics in the area to preserve and maintain the existing structure independent from political forces, it is seen that it is very important to produce authentic and quality studies that aim to focus on social problems in education and their resolution in order to develop an original and autonomous identity for the field.

\section{Results and Discussion}

In this study, researcher discusses the clarity of the boundaries of educational administration with other fields and how the quality of the studies in the field affects the originality and autonomy of the field. The existing literature indicated that the knowledge base of the field has begun to take shape under the influence of various paradigms and accordingly various views about the knowledge base of the field have emerged, especially after 1950. These views are seen as efforts to develop the field's own original identity. Studies in the field are repetitive. As a result, while the diversity of epistemological basis of the field contributes to the originality of the field, the lack of clarity of the boundaries constitutes an impediment to the autonomization of the field. Also, the studies and the academic concerns of academicians move the field away from originality and autonomy. 
Eğitim yönetimi dünyası son yıllarda büyük bir değişim yaşamaktadır. Ancak eğitim kurumlarını incelemek için kullanılan teoriler aynı ölçüde epistemolojik ve ontolojik gelişime sahip değildir. Yani, bir disiplin alanı olarak eğitim yönetimi büyüklük ve anlam kazanırken, liderlik programlarının küresel ölçekte hızlı bir şekilde gelişme göstermesi bir kenara konulduğunda, alanın giderek zorlanan bir konumda olduğu görülmektedir. Eğitim yönetimi bölümlerinin kurulmasından bu yana alanın sınırları oldukça bulanıktır. Politika çalışmalarındaki artış, eğitim sosyolojisinin genişliği ve diğer alanlar eğitim yönetimi alanına doğru yönelme göstermişlerdir (Eacott, 2015). Alanın 1950'li yıllarda, bilim felsefesindeki hakim pozitivizm bakış açısından etkilendiği ve bu süreçte bilimleşmesinin hız kazandığı görülmektedir. İzleyen yıllarda ise post-pozitivizm olarak nitelendirilen yaklaşımlarla alanın epistemolojik ve metodolojik temeline ilişkin görüşler çeşitlenmektedir. Eğitim yönetimi, kamu hizmeti olarak görüldüğ̈̈ için, 20. yüzyıl başlarında kamu yönetiminin bir alt dalı olarak tanımlanmıştır. 1980'li yıllara gelindiğinde ise pozitivizmin ağır eleştirisinin yapıldığı ve alanın kamu yönetiminin çatısı altından işletme yönetiminin çatısı altına doğru kaydığı görülmektedir. Buradan hareketle alanın özerk kimliğini geliştiremediğini söylemek mümkündür (Özdemir, 2011).

Çoğu bilim dalı ve ya çalışma alanı doğasına uygun yöntem geliştirmeye ve özgün bir kimlik edinmeye çalışmaktadır. Eğitim yönetimi de bir bilim alanı olarak hiç kuşkusuz zaman içerisinde böyle bir çaba içerisine girmiştir. Balcı'ya (2008) göre eğitim yönetimin doğası gereği üç temel boyutu bulunmaktadır ve bunları şu şekildedir; pratik bilgi, profesyonel meslek bilgisi ve akademik bilgi. Alanın kimliğini günümüzde bu üç bilgi kümesi oluşturmaktadır. Fakat alanın kimliği sosyal, politik, ekonomik ve bilimsel gelişmelerle birlikte değişme ve gelişme göstermekte, göstermeye de devam edecektir. Önemli olan ise eğitim yönetimi alanının gelecek için özerk ve özgün bir bilim olmayı hedeflemesidir. Özgünleşme kavramı Türk Dil Kurumu Sözlüğünde (2018) "yalnız kendine özgü bir nitelik taşıyan, orijinal" şeklinde tanımlanan özgün kelimesinden türemekte ve "özgün duruma gelme" olarak tanımlanmaktadır. Özerkleşme ise Türk Dil Kurumu Sözlüğünde (2018) "yönetim bakımından kimi koşullar altında bağımsız hareket edebilme" şeklinde tanımlanmaktadır. Bu tanımlardan yola çıkarak, eğitim yönetimi alanı kendine özgü bir nitelik taşımakta mıdır, alanda yapılan çalışmalar orijinal midir, alan diğer alanların etkisinde ne kadar kalmaktadır, diğer alanlarla olan sınırlarını çizebilmekte midir ve diğer alanlardan ne derece bağımsız hareket edebilmektedir sorularının cevabı, alanın özgünlüğü ve özerkliğinin anlaşılmasında bizlere yardımcı olacaktır. Bu bağlamda çalışmanın amacı eğitim yönetimi alanının özgünleşme ve özerkleşmesini etkileyen etmenlerin irdelenmesidir. $\mathrm{Bu}$ genel amaç doğrultusunda aşağıdaki sorulara yanıt aranmıştır:

1. Alanın bilgi temeline ilişkin gelişmeler alanın özgünlük ve özerkliğini nasıl etkilemektedir?

2. Alan diğer alanlarla olan sınırları alanın özgünlüğünü ve özerkliğini nasıl etkilemektedir?

3. Alanda yapılan çalışmaların niteliği alanın özgünlük ve özerkliğini nasıl etkilemektedir?

\section{Alanın Bilgi Temeline ilişskin Gelişmeler}

Eğitim yönetiminin tarihi ve bilimleşme serüvenine geçmeden önce eğitim yönetiminin tanımını yapmak daha doğru olacaktır. Özdemir (2018) eğitim yönetiminin hem bir bilim hem de uygulama alanı olduğunu ifade etmiş ve bir uygulama alanı olarak eğitim yönetimini, "bir ülkedeki eğitim hizmetlerinin örgütlenmesi ile eğitimin genel ve özel amaçlarının başarılmasına odaklanan yönetsel faaliyetler bütünü" şeklinde tanımlarken bir bilim alanı olarak ise "eğitimdeki yönetsel olguları inceleyen bir bilim dall" (Özdemir, 2018; s.5) şeklinde tanımlamaktadır. Bir alanın kurumsallaşmasıyla o alanın bilimleşme yoluna girip özerk bir bilim olması arasındaki ilişki (Balcı, 2008) göz önüne alınarak, Gulbenkian Komisyonu'nun hazırlamış olduğu Sosyal Bilimleri Açın adlı raporda bulunan bir bilimin kurumsallaşma ölçütleri aşağıdaki gibi sıralanmaktadır (2016):

1. Üniversitelerde bölüm ve ya kürsülerinin bulunması

2. Araştırma alanının olması

3. Diplomaya götüren programların sunulduğu bölüm ve ya birimlerinin olması

4. Ürünlerini sunma olanağı tanıyan bilimsel dergilerin olması

5. Üyelerinin örgütlenmesi.

$\mathrm{Bu}$ ölçütler dikkate alındığında kurumsallaşma süreci içinde eğitim yönetimi alanın bir bilim dalı olduğunu söylemek mümkündür (Özdemir, 2011; Balcı, 2008). Ancak eğitim ve eğitim yönetimi kavramlarının insanlık tarihi kadar gerilere gittiği bilinse de sistemli bir çalışma alanı olarak eğitim yönetimi tarihi, diğer disiplinler gibi çok gerilere gitmemektedir (Balc1, 2008; Hyung, 2001; Opltaka, 2010; Özdemir, 2011). 
Eğitim yönetimi öncellikle bir meslek alanı olarak 19. yüzyılın son çeyreğinde ortaya çıkmıştır ve daha sonra bir bilim alanı olarak Amerika Birleşik Devletleri'nde üniversitelerde gelişme göstermeye başlamıştır. (Oplatka, 2010; Özdemir, 2011). 19. yüzyılın ikinci yarısında okul liderliği programları yaygınlaşmaya ve denetim gelişmeye başlamıştır. Bu dönemde William L. Payne okul yönetimiyle ilgili ilk kitabı yazmış ve okul yönetimi alanında üniversite düzeyindeki ilk dersleri 1879 yılında Michigan Üniversitesinde vermeye başlamıştır (Brundrett, 2001; Papa, 2009). 20. yüzyılın ilk yıllarına gelindiğinde ise eğitim ve yönetim alanını etkileyen ideolojilerden birisinin örgütlerde etkililik ve verimlilik üzerinde duran Taylor'un bilimsel yönetim ilkeleri olduğu görülmektedir. Eğitim yönetimi alanının öncüleri arasında görülen Strayer, Cubberly, Thorndike ve Ellwood gibi alandaki bilim insanlarının Taylor'dan etkilenerek okulların verimlilik ve etkililiği üzerine çalışmalar gerçekleştirdiği görülmektedir (Watkins, 1986; Oplatka, 2010; Özdemir, 2017). Buradan hareketle dönemin biliminsanları daha çok işletme yönetimine özgü yaklaşımları ve kavramları kullanarak alanın bilgi temelini oluşturmaya başladıklarını söylemek yanlış olmayacaktır. Nitekim 20. Yüzyıl başlarında Amerikan üniversitelerinde eğitim yönetimi alanında tezler incelendiğinde tez konularının daha çok okulun mali idaresi, öğrenci ve personel yönetimi, bina ve teçhizat gibi konular üzerine yoğunlaştı̆̆ dikkat çekmektedir (Callahan, 1962; akt. English, 2002). Üniversitelerde okutulan derslere bakıldığında da liderliğin ön plana çıkmadığı, üzerinde durulan konunun ise verimlilik olduğu görülmektedir (English, 2002). 20. yüzyılın ilk yıllarında eğitim yönetiminde bilimsel yaklaşıma olan bu yönelim günümüzde de kendini hissettirmektedir. Üniversitelerin eğitim yönetimi alanında okutulan derslere bakıldığında, eğitim yönetimi alanındaki kitaplar incelediğinde bu yönelimin izleri dikkat çekmektedir.

1950'li yıllar ise birçok çalışmada eğitim yönetimi alanında Teori Hareketi’nin ortaya çıktığ 1 yıllar olarak gösterilmektedir (English, 2002; Hyung, 2001; Özdemir, 2017; Riffel, 1978). O dönemde bu hareketi etkileyen bazı gelişmeler yaşanmıştır. Bu gelişmeler arasında alanın bilim insanlarını bir araya getiren 1947'de gerçekleştirilen Ë̆itim Yönetimi Profesörleri Ulusal Konferansı, 1950'de Kellogg Vakfı tarafindan başlatılan Ĕ̆itim Yönetimi İsbirliği Programı ve 1956 yılında Eğitim Yönetimi Üniversite Konseyi’nin kurulması yer almaktadır (Özdemir, 2018; Riffel, 1978). Ayrıca pozitivizme dayalı bilim felsefesi bu dönemdeki çalışmaları büyük ölçüde etkilemiş ve Teori Hareketi’nin dayanağını oluşturmuştur (English, 2002; Hyung, 2001; Özdemir, 2018). Mantıksal pozitivizmin Teori Hareketine olan etkisinin anlaşılabilmesi için iki bilim insanının çalışmaları oldukça önemlidir. Bunlardan ilki Herbert Simon ve diğeri de Daneiel Griffiths. Griffiths örgüt bilimin fizik ya da matematik gibi görülebileceği konusundaki görüşlerini zaman içerisinde terk etmiş olmasına rağmen, eğitim yönetimi alanının pozitivist doğasını şekillendiren önemli bir bilim insanıdır (Hyung, 2001).

Herbert Simon'ın 1945 'de yayımlanan Yönetimsel Davranış adlı çalışması yönetim anlayışına ve çalışmalarına yeni bir yaklaşım oluşturmuştur. Yönetimin doğasına ilişkin tamamen yeni bir bakış açısı getirmiş ve daha önemlisi yönetimsel gerçekliklerin sorgulanmasında yeni bir kurallar dizini oluşturmuştur. Simon'a göre yönetimsel bilginin oluşturulması ve geçerliliğinin sağlanması nesnellik ve bilimin kullanılması ile mümkündür yani değerlerden bağımsız olmalıdır (Greenfield, 1986).

Simon'ın karar vermeye odaklanan yönetim anlayışı ve yönetici kararlarının rasyonelliğinin geliştirilmesi için pozitivist bilimin yöntemlerinin kullanılması gerekliliğine olan inancı alandaki çalışmaları baskın bir biçimde şekillendirmiştir. Pozitivizm ruhu, eğitim yönetimi alanına 1950'lerde Halpin'in (1970) deyimiyle Teori Hareketi adıyla yayılmaya başlamıştır. Fiziksel dünyanın kontrol edilmesini mümkün kılan bir teori gibi eğitim örgütlerinin de kontrol edilmesini mümkün kılacak bir teori üretilmesi, bunun yöneticilere öğretilmesi ve kullanılmasının sağlanması Teori Hareketinin amacıdır (Greenfield, 1986). Yani bu hareketin temsilcileri alanda genel-geçer yasalar ortaya koymaya çalışmışlardır. Ayrıca bu hareket, örgütlere rehberlik edecek nesnel bir bilimin keşfedildiğine dair inancı geçerli kılmıştır. Bu inanç geniş çapta kabul görmüş ve yöneticilerin üniversitelerde açılan programlarda eğitim görmesi fikri yayılmıştır. Örgüt bilimini öğreten bu programlar devlet denetimi altına alınmış ve diploma verilmesi sağlanmıştır (Greenfield, 1986). Buradan hareketle Teori hareketinin eğitim yönetiminin kurumsallaşmasını ve dolayısıyla bilimleşmesini önemli ölçüde etkilediği söylenebilir. Ancak 1970`li yıllara gelindiğinde Teori hareketine yönelik eleştirilerin yapılmasına rağmen, alanın epistemolojisine ilişkin ciddi tartışmaların yer almadığı ve bu konunun üzerinde durulması gerektiğine yönelik görüşler de ortaya çıkmıştır. Willower (1975) ve Riffel (1978) bu yöndeki tartışmaların eğitim yönetimi alanına daha bilimsel bir yaklaşımın katacağını ve alanın olgunlaşmasını sağlayacağını belirtmişlerdir.

20. yüzyılın son on yıllarında, 2. Dünya Savaşı'ndan sonra ortaya çıkan ve okul yönetimini bir bilim dalı olarak gören paradigma anlayışından kopma söz konusudur. 1960'lı yıllardan sonra okula yönelik eleştiriler artmaya başlamıştır. Freire ve Illich gibi eleştirel pedogoji alanındaki bilim insanları okulun bireyi tek tipleştirmesi, hakim olan ideolojiye göre birey yetiştirmesi yönünde eleştirilerde bulunmuşlardır. Genelde eğitimdeki bu yaklaşım özelde eğitim yönetiminde de yankı uyandırmıştır. Feyerabend, Kuhn, Popper gibi bilim filozoflarının mantıksal pozitivizmin ana fikirlerini çürütmesiyle, eğitim yönetiminde teorik açıdan baskın olan geleneksel bilim görüşlerine özellikle öznelcilik ve eleştirel teori ile meydan okunmaya başlanmıştır. Özellikle 1970'li yılların başından araştırmalarda kullanılan yöntem ve alanın kavramsal konumlandırılmasına ilişkin eleştiriler 
artmaya başlamıştır (Beycioğlu ve Dönmez, 2006; Hyung, 2001; Özdemir, 2017; Riffel, 1978). Özellikle Teori hareketinin benimsediği değerlerin örgütten arındırılması ve Teori hareketinin yönetimi sadece teknik ayrıntılara indirgemesi yönünde farklı görüşler dile getirilmiştir. Teori hareketinin eleştirisini yapan en önemli muhtelif seslerden birisinin Greenfield olduğu söylenebilir. Greenfield (1986) üniversitelerde açılmaya başlanan yönetici yetiştirmeye yönelik programların pozitivist anlayışa dayandığını, sadece mantıklı ve rasyonel kararlar alabilen yöneticilerin yetiştirilmeye çalışıldığını, bu durumdan ise egemen güçler ile yönetim biliminin karşılıklı fayda sağladığını dile getirmiştir. Ancak örgütler insan yapımı sosyal gerçekliklerdir ve tamamen değer yüklüdürler. Örgütü değerlerden ayrı düşünmek doğru bir yaklaşım değildir. Ayrıca bilim insanı sadece gerçeği gözlemleyen değil aynı zamanda yorumlayan kişidir. Bu nedenle insanın ilgileri, ön yargıları bilimsel doğru ile iç içe geçmiş şekildedir. Bu anlayış eğitim yönetimi çalışmaları için de geçerlidir (Greenfield, 1986) diyerek alanda sadece nicel çalışmaların yapılmasını da eleştirmektedir.

Greenfield gibi Bates de geleneksel teoricilerin değerlerden arınık yönetim anlayışını güçlü bir şekilde karşı çıkmıştır. Bates, bilim felsefesindeki gelişmelere rağmen eğitim yönetimindeki ana akım teoricilerin hala pozitivizmin görüşünü temele aldıklarını, eğitim örgütlerinin ekonomik, sosyal ve politik etkenlerle olan ilişkisini görmezden geldiklerini ifade etmiştir. Eğitim yönetiminin, daha iyi bir toplum yaratmak adına katılımc1 demokrasi ve insanın özgürleşmesi gibi kolektif sosyal değerlerle daha çok ilgilenmesi gerektiğini öne sürmüştür (Hyung, 2001; Özdemir, 2017).

1980’lerde okul yöneticisi algısını radikal bir șekilde değiștiren standartlar hareketi geliștirilmiștir. Bu standartlar bilimsel çalışma ya da araştırmadan ziyade, okul yöneticilerinin uygulamaya ilişkin beyanları doğrultusunda oluşturulmuştur. Eğitim yönetiminin vizyonu ölçülebilir bilimsel gerçeklikle ilgili çalışmalardan okul liderliğinde kalite çalışmaların yapılmasına doğru değişim göstermiştir. Değerler daha önemli hale gelmiş, okul yöneticilerinden etik lider, moral lider olarak bahsedilmeye başlanmıştır. Yönetici yetiștirme programları bu anlayışa göre düzenlenmiştir. Okul liderliğindeki bu popüler yaklaşıma karşın Evers ve Lakomski eğitim yönetimi bilim alanının felsefesine ilişkin çalışmalar ortaya koymuştur. Bu çalışmalarla ortaya çıkan yaklaşım bağdaşımcllık teorisi olarak adlandırılmaktadır (Maxcy, 2001; Özdemir, 2018). Evers ve Lakomski (1996) ne pozitivizme dayalı ne de onun eleştirisini yapan bilim anlayışından yana durmuşlardır. Bilginin gerekçelendirilmesinde bağdaşımcı yaklaşımı benimsedikleri yeni bir bilimden bahsetmişlerdir. Evers ve Lakomski'ye göre (2001) bilgiye ve onun gerekçelendirilmesine post-pozitivist bir bakış açısı bilimin daha iyi anlaşılmasını sağlayacaktır. Eğitim yönetiminde teori, global bir inanç sistemi ağıdır. Matematik, mantık gibi doğa bilimi bu ağ sisteminin merkezinde yer almakta ve önemli örgütsel bir rol oynamaktadır. Bu sistem insan öznelliğine ve ahlaki konulara uzanan bir bütündür (Evers ve Lakomski, 2001). Hyung'a göre (2001) naturalistik bağdaşımcılar beynimizdeki şekil tanıma gibi, teoriye fiziksel bir açıdan bakılmasının eğitim alanında teori ve uygulama arasındaki uçurumu azaltacağını ileri sürmektedirler. Herhangi bir teori akademik önermelerde bulunur ve bu tür bilgilerin eğitim uygulayıcılarına pek bir faydası dokunmaz. Bu durum uygulama ve teori arasında bir farklılaşmaya neden olmaktadır. Aslında eğitimdeki teoriler ve uygulamalar birbirini beslemektedirler; teorideki gelişim uygulamayı, uygulamadaki gelişim de teoriyi etkilemekte ve geliştirmektedir. Naturalistik bağdaşımcılar buna benzer bir sentezin sağlanmasına yardımcı olmuşlardır.

Bir alanın kurumsallaşmasıyla o alanın bilimleşme yoluna girip özerk bir bilim olması arasında ilişki (Balcı, 2008) göz önüne alındığında eğitim yönetimi alanının bilimleşme sürecinin ele alındığı bu bölümde alanın kurumsallaşma sürecine de yer vermenin doğru bir yaklaşım olacağı düşünülmektedir. Eğitim yönetimi alanına bir dönem damga vuran ve hala etkileri hissedilen Teori hareketine yapılan eleştirilere rağmen, alanın çalışma alanı olarak yasallık kazanmasını sağlamıştır. Bu dönemde başta Amerika ve daha sonra da batılı ülkeler olmak üzere birçok üniversitede diplomaya götüren eğitim yönetimi programları açılmış, araştırmalar hacim ve nitelik kazanmış, araştırmacılar çalışmalarının devlete kurumları tarafından finanse edilmeye başlanmıştır (Oplatka, 2009).

Oplatka (2009) tarafından kurumsallaşma dönemi olarak ifade edilen 1960'lı ve 70'li yıllar, dönemin neslini etkileyen olaylar, süreçler ve paradigmalar tarafindan belirlenmiştir. Bu süreç, birçok batılı devlet için sivil haklar hareketinin yoğunluk kazandığı ve refah devlet olma süreci olarak belirtilmiş̧ir ve ayrıca bu dönemde liderliğin başlıca rolleri oluşturulmuştur. 1970'lerin sonunda etkili okul hareket başlamıştır. Bu dönemde bir çalışma alanı olarak eğitim yönetimi Amerika'dan diğer ülkelere yayılma göstermeye başlamıştır. Avrupa'da, Avustralya'da ve dünyanın çeşitli yerlerinde alanı geliştirmesi, entelektüel ve deneysel çalışmaların değiş tokuşunu olanak sağlaması amacıyla British Educational Management Association (BEMA), Australian Council for EA, the Commenwealth Council for EA (CCEA), the European Forum on EA (EFEA) gibi çeşitli meslek örgütleri kurulmuştur (Oplatka, 2009).

$\mathrm{Bu}$ gelişmelere paralel olarak alanın ilk akademik yayınları da bu dönemde hayata geçmiştir. Journal of Educational Administration (JEA), Educational Administration Quarterly (EAQ), Educational Management Administration and Leadership (EMAL) alanda ilk yayınlanan dergiler arasında yerini almıştır (Oplatka, 2009; Özdemir, 2018). Bu dergiler alanda yapılan uygulama, eğitim ve araştırmalara dair bilgilerin yayılmasını 
kolaylaştırmak, entelektüel ve ampirik tartı̧̧malar için bir forum sağlamak, uygulayıcıların ihtiyaçlarını karşılamak, yerel grupların oluşumunu teşvik etmek gibi çeşitli amaçlara sahiptir (Oplatka, 2009).

Eğitim yönetiminin bilimleşme süreci incelendiğinde bir çalışma alanı olarak yaklaşık yüz elli yıllık bir geçmişi olduğunu söylemek yanlış olmayacaktır ve özellikle 1940 'lı yıllardan sonra alanın bilgi temeline ilişkin çeşitli görüşlerin zaman içerisinde ortaya çıktığı görülmektedir. Burada önemli olan bir dönemin sonlanıp diğer dönemin başlaması gibi bir sürecin söz konusu olmayışıdır. Kuramsal bir dönem başladıktan sonra bitebilir, devam edebilir ya da kuram yeniden gündeme gelebilir. Nitekim Teori Hareketinin günümüzde etkisinin hissedilmesi bu duruma örnek olarak verilebilir. Önemli olan kişinin olayları incelerken ve çalışmalarını yürütürken nerede durduklarını, hangi bakış açısını kullandıklarının farkında olmalarıdır. Nispeten kısa denilebilecek bu zaman içerisinde eğitim yönetimi alanındaki akademisyenlerin çeşitli kongrelerle bir araya gelmeye çalıştı̆ı, alanda bilimsel dergilerin yayınlandığı, üniversitelerde diplomaya götüren programların açıldığı, ampirik ve kuramsal çalışmaların giderek yoğunlaşı ğı görülmektedir. Hiç kuşkusuz bu tür gelişmeler bir bilim alanının özerkleşmesi ve özgünleşmesine katkıda bulunacak türden gelişmelerdir. Ancak bu tür gelişmelerin niteliğinin alanın özgünlüğünü ve özerkliğini sağlayacağı da göz ardı edilmemelidir. Bu bağlamda çalışmanın devamında alanın, diğer alanların etkisinde ne kadar kaldığı, diğer alanlarla olan sınırlarını net bir şekilde çizip çizemediği, alanda yapılan çalışmaların orijinal olup olmadığı gibi sorular cevaplandırılmaya çalışılmıştır.

\section{Eğitim Yönetimi Alanının Sınırları}

Eğitim yönetimi alanının her zaman kendi özgün kimliğini oluşturma gayreti içerisinde olmasına rağmen bunu başaramamasının başlıca nedenlerinden birisi alanın işletme yönetimi, kamu yönetimi, iktisat gibi diğer alanlarla arasındaki sınırları tam olarak belirleyememesidir (Özdemir, 2011,2017). Bir çalışma alanının disiplinleşmesinde öne çıkan konulardan birisi alanın sınırlarının belirlenmesidir. Güçlü bir paradigma ya da düşünce belirli bir zaman diliminde belirli bir disiplin alanında baskın konumda olabilir. Ancak disiplinler durağan değildir. İlişkili disiplinlerdeki gelişme ve yöntemlerden etkilenebilirler. Sonuç olarak bazen disiplinler arası sınırlar net bir şekilde belirli değildir. Disiplinin epistemolojik yapısı, disiplinler arası sınırların belirlenememesinde önemli bir rol oynar (Donmoyer 2001; Klein, 1993). Özellikle pozitivizme dayalı Teori hareketi döneminde eğitim yönetimi alanında model geliştirmeye yönelik istek, sosyal bilimlerin sosyoloji, politika, sosyal psikoloji gibi farklı disiplinlerinde var olan teorilerin eğitim yönetimi çalışmalarında kullanılmak üzere alana aktarılmasına neden olmuştur (Riffel, 1978).

Oplatka'ya göre (2009) sosyal ve politik güçlerin bir bilim alanının diğer bilim alanlarından ayrılması ve sınırlarının belirlenmesi üzerinde etkisi vardır. Eğitim yönetimi alanı 1980'li yıllara kadar kamu yönetiminde gözlenen merkezileşme ve genişleme eğiliminin etkisinde kaldığı, 1980'li yıllardan sonra ise ekonomideki liberal yaklaşımın sonucu olarak işletme yönetiminden aktarılan toplam kalite yönetimi, stratejik yönetim gibi yaklaşımların etkisi altında kaldığı görülmekte ve kendi özerk kimliğini oluşturamadığı sonucuna ulaşılmaktadır (Özdemir, 2011). Aslında bir alanın var olan hakim anlayıştan etkilenmesi kaçınılmaz görünmektedir. Ancak alanın var olanı doğrudan almasından ziyade kendi ihtiyaç ve özellikleri doğrultusunda teoriler ve uygulamalar geliştirmesi beklenmektedir. Nitekim eğitim yönetiminin de ekonomideki liberal yaklaşımdan etkilenmesi kaçınılmazdır. Ancak bu etkilenme işletme yönetiminden stratejik yönetim ya da toplam kalite yönetimi gibi yaklaşımları alması ve uygulaması anlamına da gelmemelidir. Bu durum bu şekilde benimsenen ve uygulanan yaklaşımların işe yaramadığı ya da yaramayacağı anlamına gelmemektedir. Ancak eğitim yönetiminin kendi örgüt yapısını, ihtiyaçlarını vb. göz önünde bulundurarak değişen sosyo-ekonomik, politik ve toplumsal paradigmalar doğrultusunda teori ve uygulamalar geliştirmesi beklenmelidir. Bu şekilde gelişme gösteren eğitim yönetimi alanının daha özerk bir bilim dalı olduğu düşünülebilir.

Eğitim yönetimi alanında kuramsal bilgi üretmedeki sıkıntıların nedenlerinin başında alanın bilgi temelinde görüş birliğinin sağlanamamış olması gelmektedir (Beycioğlu ve Dönmez, 2006). Özdemir (2017) bilim insanlarının alanın bilgi temeline ilişkin görüş birliğine varamamasını epistemik bunalım, Waite (2002) paradigma savaşı, Griffiths (1979) ise bu çıkmazı entelektüel karmaşa şeklinde ifade etmektedir. Ancak alanın bilgi temeline ilişkin görüş birliğinin sağlanamamış olması, alanın özgün bir kimlik kazanma yolundaki çabaları olarak görülebilir. Nitekim hem pozitivist akımların hem de 1970'li yıllardan sonra örgüt ve yönetim alanında kendini göstermeye başlayan pozitivizm ötesi akımların (eleştirel kuram, bilişsel kuram vb.) eğitim yönetimi alanında kendini göstermeye başlamıştır. Teori Hareketi, Bates'in eğitim yönetimi alanına eleştirel yaklaşımı, Evers ve Lakomski'nin bağdaşımcllık teorisi bu duruma örnek olarak gösterilebilir. Bu tür çabalar da eğitim yönetimi alanın kendi bilgi temelini oluşturma çabaları ve dolayısıyla özgün bir bilim alanı olma girişimleri şeklinde değerlendirilebilir.

Kuramsal gelişmeler 1950'li y1llardan itibaren pozitivizm etkisi altındaki dönem ve pozitivist görüşlerin eleştirildiği ve sırasıyla öznelcilik, hümanizm, eleştirel teori, kültürel teori ve post- modernizm gibi (Evers ve Lakomski, 1996) karşıt görüşlerin tartışıldığı dönem olmak üzere iki dönem şeklinde ifade edilmektedir. 1950’li 
yıllara kadar eğitim yönetimi alanı, yönetim bilimi alanındaki kuramsal gelişmeler başta olmak üzere diğer alanlardaki gelişmelerin etkisi altında kalmıştır. Örgüt ve yönetim biliminin nesnel, niceliksel ve değerlerden arınık olma iddialarına rağmen, Teori Hareketi önemli değerleri ve felsefi varsayımlar barındırmaktadır (Greenfield, 1986) ve yapılan bunca eleştiriye rağmen alanın bir bilim alanı olarak akademik meşruiyet kazanmasına yardımcı olmuştur (Oplatka, 2009).

1970’li yıllara kadar alanda kuramsal kısırlık mevcuttu. Bu tarihten sonra muhalif seslerin çıkmaya başladığı görülmektedir. Bu yıllardan sonra pozitivizm ötesi olarak nitelendirilen yorumlayıc1, eleştirel, bilişsel, simgeci ve kültürel kuramlar üzerinde durulmaya başlanmıştır (Willower ve Forsyth, 1999). Özellikle Greenfield ve Hodgkinson'ın alanda baskın olan Amerikan pozitivizmine yönelik ağır eleştirileri olduğu görülmektedir (English, 2002). Greenfield'e göre (1986) bilim insanı sadece gerçeği gözlemleyen değil aynı zamanda onu yorumlayan kişidir, bu nedenle de kişinin ilgileri ve önyargıları bilimsel gerçek ile iç içe geçmiş bir şekildedir. Greenfield alanın çok fazla pozitivist araşıırma yöntemlerini araştırmalarda kullandığ 1 yönünde eleştirilerde bulunmuş ve nesnellikten çok öznelliği savunan bir yaklaşım geliştirmiştir. Greenfield öncülüğünde başlayan, pozitivist yaklaşımı benimseyenler ile yorumsamacı yaklaşımı benimseyen bilim insanları arasındaki bu görüş̧ ayrılıkları Waite (2002) tarafından paradigma savaşı olarak isimlendirilmiştir (Oplatka, 2009). Greenfield ve Hodgkinson'ın alan yazındaki çalışmalarına rağmen alanda baskın olan Amerikan ortodoksunda ufak değişiklikler yapıldı. Bu dönem içerisinde pozitivizmin en belirgin yönlerinden vazgeçilmiştir, ama yine de kavramsal yapının sağlam bir şekilde kalmaya devam ettiği görülmektedir (English, 2002; s.120-123).

1980'li yllarda Thomas Kuhn'dan ve Frankfurt Okulu'ndan etkilenen Bates $(1980,1982)$ ve Foster (1986) eğitim yönetimine eleştirel yaklaşımı geliştirmiş̧lerdir (Balc1, 2008; Özdemir, 2017). Bu yıllardan itibaren hem fakülte hem de okul yöneticileriyle alanın çeşitlenmeye başladığı, böylece okullarda büyüyen çeşitliliği daha iyi yansıtan seslerin daha çok çıkmaya başladığı bir döneme girildiği dikkat çekmektedir. Bu dönemde okullardaki çalışmalar kadınları ve farklı ırklardan insanları daha fazla içermeye başlamış, cinsiyet ve ırk ayrımcılığı üzerine yapılan araştırmaların liderlik araştırma alanını zenginleştirmek adına eğitim yönetiminin odağında yer aldığı bir dönem olarak ortaya çıkmaktadır (Papa, 2009).

1990'lı yıllarda eğitim yönetiminde bilim arayışları başarısızlığa uğramış ve okul gelişimi ve liderlik ile ilgili söylemler yer almaya başlamıştır. Üstelik eleştirel, post-modernizm ve diğerleri sayesinde eğitim yönetimini değerlerden, etik ve ahlaki konulardan ayırma çabaları da başarısızlığa uğramıştır. Bu dönemde Evers ve Lakomski ne geleneksel bilim anlayışını ne de eleştirel kuramları olduğu gibi kabul etmiştir; onun yerine alanda yeni bir bilim anlayışı geliştirmişlerdir. Eğitim yönetiminin pozitivist ve yapılandırmacı bir bilim olarak ele alan yapıyı, bağdaşımcılık ve naturalizm temeline uyarlamışlardır (Maxcy, 2001; Özdemir, 2018).

Kısaca bu süreç içerisinde eğitim yönetimi alanına pozitivist ve yorumsamacı paradigma olmak üzere iki düşünme şeklinin ya da paradigmanın hakim olduğu görülmektedir. Her iki bakış açısııın da doğru ya da yanlış yönleri bulunmaktadır. Kişiler olayları incelerken tek bir bakış açısından yararlanmaktansa zaman zaman görüş açılarını değiştirmeleri, farklı yöntemlerle olaya yaklaşmaları gerekmektedir. Şişman (1998) da bu konuda benzer görüşler öne sürmekte, bilim insanlarının çoklu bakış açısı geliştirmesinin gerekliliğini dile getirmektedir. Alandaki akademisyenler benzer sorunlara farklı paradigma ve yöntemlerle yaklaşllabilir ve böylece daha sağlıklı sonuçlar elde edilebilir.

\section{Alanda Yapılan Çalışmalar}

Eğitim yönetimi alanında lisansüstü düzeyde yapılan çalışmaların niteliğinin alanın özgünlüğüne katkı sunacağını düşünmek kaçınılmazdır. Bu düşünceden hareketle Türkiye'de eğitim yönetimi alanında yapılan lisansüstü tezleri ve makaleleri inceleyen çeşitli çalışmalar incelenmiştir. Türkiye'de lisansüstü tezlerde ve makalelerde araştırma yöntemi olarak araştırmacıların büyük bir çoğunluğunun nicel yöntemlere başvurduğunu, çok az sayıda araştırmacının metodolojideki gelişmeleri göz önünde bulundurarak nedensel karşılaştırma ve nitel yöntemlere başvurduğu dile getirilmektedir (Balcı ve Apaydın, 2009; İşçi, 2013; Karaca, 2018; Karadağ, 2010; Kısa, 2016; Polat, 2010; Turan ve diğerleri, 2014; Uysal, 2013; Yıldırım, 2016;). Alanda yazılan lisansüstü tezlerin ve makalelerin konuları incelendiğinde, benzer konuların tercih edildiği ve bu konuların özellikle aynı dönemlerde popüler olduğu belirtilmektedir (İşçi, 2013; Kısa, 2016; Polat, 2010; Turan ve diğerler, 2014; Uysal, 2013). Ayrıca teori ve uygulama arasında bir boşluk, uzaklaşma ya da farklılaşma olduğu dile getiren çalışmalara da (Demirhan, 2015; Kisa, 2016) rastlanmaktadır.

Teori ve uygulama arasındaki uzaklaşmanın nedenleri arasında araştırma sonuçlarının paylaşılmaması, yapılan araştırmaların uygulamacıların ihtiyacına dönük olmaması, akademisyenlerin gerekli ve yeterli girişimlerde bulunmaması, uygulayıcıların ise bilimsel çalışmalara ilgisiz kalmaları yer almaktadır (Karataş, Kyzy ve Topuz, 2015; Kısa, 2016). Ayrıca yükselme ya da atanma kaygısının akademisyenlerin çalışmalarında itici güç olduğu yönünde de bulgulara yer verilmektedir (Demirhan, 2015; Kısa, 2016). Turan ve Şişman (2013) entelektüel derinliği olmayan çalışmalarla bir yere gelinemeyeceğini, bilim için bilim anlayışı ya da kariyer kaygısı ile yapılan araştırma sonuçlarının ve etkilerinin yüzeysel kalacağını ifade etmektedirler. Alanın özerk ve bağımsız 
bir bilim olabilmesi için eğitim yönetimine dair sorunların eğitim bilimcilerinin bakış açılarıyla irdelenmesi, eğitim yönetimi alanındaki akademisyenlerin güçlü bir topluluk oluşturarak kendi norm, kural ve standartlarını belirleyip çevrelerine kabul ettirmeleri gerekmektedir (Balcı, 2008). Oplatka (2010) alandaki profesörlerin uyumlu ve ayırt edilebilir bir topluluk olduğunun pek söylenemeyeceğini ama yine de genel bazı özellikleri paylaştığını belirtmiştir. Dünya genelinde üniversitelerin çeşitli bölümlerinden gelip eğitim yönetimi alanında akademik kariyerlerine devam edebilmektedirler. Ancak eğitim yönetimi alanında doktorasını tamamlayan biri gidip psikoloji veya sosyoloji alanında kendine bir pozisyon bulamaz. Bu durumun altında yatan şüphesiz ki eğitim yönetiminin çok disiplinli ve bilgi temelinin zayıf oluşudur (Oplatka, 2010).

20. yüzyıl boyunca alanda yapılan çalışmaların örgütsel öğrenme, dönüşümsel liderlik, insan ilişkileri, bilimsel yönetim teorileri gibi çeşitli alanlardan etkilenerek gerçekleştiği görülmektedir. 1950'li y1llardan önce alanın bilgi temeli deneysel çalışmalara dayanmamakta, daha çok önceki yöneticilerin kendi deneyimlerine dayanan ve reçete niteliğinde sunduğu uygulama tavsiyelerine dayanmaktadır. 1950'lilerin başında teori hareketiyle birlikte kişisel tecrübe, ideolojik inanç ve reçetelerden ziyade deneyselliğe dayanan bilgi üretme çabaları başlamıştır. Teori hareketinin bilimsel bilgi üretme gayesi çok kolay bir şekilde gerçekleşmemiş, sert eleştiriler almıştır. Bates ve Greenfield nicel yöntemlerin okul gibi sosyal yapıları anlamak için uygun olmadığını belirtmişlerdir. 1990'larda eleştirel teori, postmodernizm ve feminizm gibi farklı bakış açılarının yansıdı̆̆ı bilimsel araştırmaların sayısında artış görülmüştür. Fikir birliği sağlanamasa da örnek olay incelemesi, natüralistik sorgulama yöntemleri yaygınlık kazanmıştır (Heck ve Hallinger, 2005). Kavramsal çerçeve ve metodlardaki bilimsel çeşitlilik, alanda yeni problemlerin yaşanmasına neden olmuştur. Farklı kavramsal ve metodolojik yaklaşımlar benimseyen araştırmacıların birbirinden haberi yoktur. Farklı sorular sorarlar ve araştırmalarını farklı epistemolojik temellere dayandırırlar. Bu büyük çeşitlilik, bir bütün olarak alana büyük bir bilgi birikimi sağlamamaktadır. Çeşitli bakış açılarından gerçekleştirilen çalışmaların sonuçları, uygulayıcılara ve yetkili mercilerin kullanabileceği somut deliller sunamadığı görülmektedir (Gunter ve Fitzgerald, 2008; Richmon and Allison, 2003; Robinson, 1996; Akt. Heck ve Hallinger, 2005). Türkiye'de alanda yapılan çalışmalara bakıldığında da araştırmacıların pozitivist paradigmaya bağlı oldukları ve pozitivist yöntemlere dayalı elde ettikleri bulgularla var olan durumu koruyan nitelikte bilgiler üretildiği (Örücü ve Şimşek, 2011; Şişman, 1998) ve alana ilişkin sorunları irdelemek ve dönüştürmekten uzak olduğu görülmektedir (Turan, 2004). Beycioğlu ve Dönmez ise (2006) Türkiye'de eğitim yönetimi alanın kuramsal nitelikteki çalışmaların az olmasını akademisyenler ve üniversiteler arası iletişimin olmaması ve kopukluğun yaşanması, çalışmalarda kullanılan yöntemlerde çoğunlukla pozitivizm etkisinin görülmesi, alanın kuramsal temelleri incelenirken çok disiplinli yaklaşımdan uzak kalınması ve sosyal bilimlerin diğer alanlarına yabancılaşmanın yaşanmasına bağlamaktadır.

Hem araştırmalarda hem de yayınlarda ele alınan konuların aynı dönemlerde benzer konular üzerine odaklandığı ve benzer yöntemler ki bunun da çoğunlukla nicel yöntemler olduğu dikkat çekmektedir. Ayrıca yapılan çalışmaların hakim paradigmalar ışığında yapıldığını söylemek de yanlış olmayacaktır. Oysaki var olan problemlere göz önünde bulundurmanın ve popüler konuları tekrarlamaktan kaçınmanın teori ve uygulama arasında da bir bağ oluşturacağını düşündürmektedir. Turan (2004) eğitim yönetimi alanında üretilen bilgilerin zamana ve yere göre değişebileceğini, bilginin toplumun kültürel ve tarihine göre değişiklik gösterdiğini bu nedenle de bilginin evrenselliğinden bahsedilemeyeceğini ifade etmektedir. Fakat Türkiye'de Batılı ülkelerde yapılan çalışmaların Türkiye için geçerli olabileceği düşünülmekte ve ölçek çevirme ve uyarlama çabalarına girilmektedir. Bu çabanın temelinde yatan düşünce, diğer toplumların kendine özgün koşullarda ürettikleri bilginin, bilginin aktarıldığı toplum içinde geçerli olabileceği düşüncesidir (Turan ve Şişman, 2013). Ancak böyle bir yaklaşım alan da yapılan çalışmaları özgünlükten uzaklaştıracaktır. Bu nedenle alanın hem yerelde hem de uluslararası düzeyde özgünleşmesine katkı bulunacak olan kültürel ve toplumsal sorunlar doğrultusunda alandaki çalışmalara yön verilmesi gerekliliğidir.

\section{Sonuç ve Tartışma}

Eğitim örgütlerindeki yönetsel olguları inceleyen eğitim yönetimi, yönetim ve eğitim bilimleri arasında gelişme gösteren ve bu iki bilim alanıyla sınırlarını belirleyerek özerkleşmeye çalışmaktadır (Özdemir, 2018). Gulbenkian Komisyonu'nun hazırladığı Sosyal Bilimleri Açın (2016) raporundaki bilim olmanın ölçütleri dikkate alındığında eğitim yönetimi alanının bir bilim dalı olduğunu söylemek mümkündür (Özdemir, 2011). Ancak bilimlere özgünlük ve özerklik kazandıran ölçütler ise farklıdır. Bu çalışmada eğitim yönetiminin diğer alanlarla olan sınırlarının netliği ve alanda yapılan çalışmaların niteliğinin alanın özgünlük ve özerkliğini nasıl etkilediği tartışılmaya çalışılmıştır.

Bir disiplin alanının özgün ve özerk kimliğini kazanmasında alanın sınırlarının belirlenmesinin önemli olduğu önceki bölümlerde dile getirilmiştir. Alanının sınırlarını belirlenmesinde epistemolojik yapısının önemi (Klein, 1993) göz önünde bulundurulduğunda baskın olan bilim anlayışı doğrultusunda kuram ve model geliştirme çabaları ile diğer disiplinlerden kavram, kuram ve yaklaşımların alana aktarıldığı görülmektedir. Ancak eğitim yönetiminin kuramsal temellerinin genel yönetim kuramlarından yararlanmasına rağmen 1950'li yıllarda Teori 
hareketiyle birlikte kendine özgü kuramlar geliştirmeye başladığı görülmekte ve bu kuramsal gelişmenin özellikle 1970'li yıllardan sonra ivme kazandığı dikkat çekmektedir. Özellikle her ne kadar başarısızlığa uğramış olarak görülse ve eleştiriler alsa da Teori hareketiyle birlikte başlayan ve alanın bilgi temeline ilişkin öznelcilik, eleştirel eğitim yönetimi, postmodernist ve natüralist bağdaşımcılık gibi farklı yaklaşımlar doğrultusunda çeşitli görüşlerin alanın bilgi temelini zenginleştirmesi, eğitim yönetiminin özgün bir kimlik kazanma çabalarına ivme kazandırmış̧ır. $\mathrm{Bu}$ nedenle eğitim yönetiminin işletme yönetimindeki gelişmelerden etkilenmesine ve yararlanmasına rağmen kendine özgü kuramsal bir temele sahip olduğu söylenebilir.

Türkiye açısından bakıldığında ise eğitim yönetiminde kuramsal alanda yapılan çalışmaların yeteri kadar incelenmediği ve teorik çalışmaların sınırlı olduğu çeşitli çalışmalarda (Beycioğlu ve Dönmez, 2006; Örücü ve Şimşek, 2011; Şişman, 1998; Turan ve diğerleri, 2014) dile getirilmiştir. Bu durumun nedeni ise Örücü ve Şimşek (2011) tarafindan akademisyenlerin yabancı dil sorunu, iletiş̧im yetersizlikleri, iş yükünün fazla ve akademisyen sayısının yeterli olmaması olarak belirtilmektedir. Türkiye'de yaşanan bu durumun eğitim yönetimi alanının tam anlamıyla özgün ve özerk bir kimlik kazanma çabalarının önüne geçtĭgi düşünülmektedir. Buna bağlı olarak alanın epistemolojik temeline ilişkin yapılan çalışmaların derinlik kazanması alanın bilgi temelinin zenginleşmesini ve bu şekilde de alanın özgünleşmesini ve özerkleşmesini sağlayabilir. Bu türde çalışmaların ortaya çıkabilmesi için yetiştirilen yeni akademisyen adaylarının alanın bilgi temeline hakim olması gerekmektedir. Burada en büyük sorumluluk, akademisyen adaylarının bakış açısını değiştirebilecek alandaki değerli akademisyenlere düşmektedir. Nitekim Sezgin, Kavgacı ve Kılınç (2011) tarafindan gerçekleştirilen çalışmada eğitim yönetimi alanında öğrenim gören lisansüstü öğrencilerinin kuram ve uygulama arasında ilişki kurmada, yöntem ve tekniklerin kullanılmasında, ülke sorunlarına çözüm getirecek çalışmalar yapmada sorun yaşadıklarını belirtmektedir. Ayrıca yine aynı çalışmada lisansüstü öğrencilerinin alanın öğretim üyelerinden yaşadıkları sorunları giderilmesi konusunda büyük bir beklenti içinde oldukları ifade edilmektedir.

Bir bilim alanının özerkliğinden ve özgünlüğünden bahsedebilmek için hiç kuşkusuz o bilim alanında bağımsız akademisyen topluluğunun varlığından söz etmek gerekmektedir. Ĕ̆itim yönetimi tarihine bakıldı̆̆ında 1940'lı ylllardan itibaren alandaki akademisyenlerin bir araya gelme çabaları günümüze kadar gelişme göstermiştir (Özdemir, 2018). Alandaki bilim insanlarının bir araya gelmesi oldukça önemlidir. Oysaki Türkiye'de eğitim yönetiminde akademisyenlerin işbirliği açısından ulusal ve uluslararası düzeyde geri kaldıkları Turan ve diğerleri (2014) ve Doğan ve Tok (2018) tarafından yapılan çalışmalarda dile getirilmektedir. Bunun nedeni ise makalelerin çok yazarlı olmasının akademisyenlerin ilerleme ve yükselmenin önüne geçmesi şeklindedir. Alandaki akademisyenlerin işbirliği içerisinde çalışması kadar politik güçlerden bağımsız bir şekilde çalışmalarını yürütmeleri de oldukça önemlidir. Alanın özgünleşmesini ve özerkleşmesini sağlayacak olan, var olan yapının korunmasını ve sürdürülmesine yönelik çalışmalardan çok, eğitimdeki toplumsal sorunlara ve bu sorunların çözümüne eğilen çalışmaların yapılmasıdır. Bu bilimsel çalışmalarda uygulayıcıların faydalanması için gerekli girişimlerde bulunulmalı ve alandaki akademisyenlerin iş birliği içinde hareket etmelidir. Ayrıca uygulayıcıların da alandaki bilimsel çalışmalardan haberdar edilmesine yönelik girişimlerde bulunulmalıdır. $\mathrm{Bu}$ şekilde alanın gerçek hayattan soyutlanmasının önüne geçilebilir.

Ayrıca alandaki akademisyenlerin özgün, kaliteli çalışmalar ortaya koyması da bu topluluğun var olması kadar önemlidir. Alanın gelişmesi büyük ölçüde özgün ve kaliteli araştırmaların yapılmasına bağlıdır. Hem dünyada hem de Türkiye'de eğitim yönetimi alanında yapılan çalışma ve araştırmalara bakıldığında özgünlükten ve yaratıcılıktan uzak, basit nitelikte çalı̧̧alar olduğu görülmektedir (Balcı, 2008). Türkiye'de eğitim yönetimi alanında yapılan çalışmaların çoğunluğunun metodolojik açıdan benzer olduğu, belirli dönemlerde belirli konular üzerine yoğunlaşıldığı birçok çalışmada dile getirilmektedir (Balcı ve Apaydın, 2009; Doğan ve Tok, 2018; İşçi, 2013; Karaca, 2018; Karadağ, 2010; Kısa, 2016; Polat, 2010; Turan ve diğerleri, 2014; Uysal, 2013; Yıldırım, 2016). Bu doğrultuda alandaki akademisyen ve adaylarının ölçme değerlendirme, bilimsel araştırma, istatistiksel teknikler gibi konularda iyi bir şekilde yetiştirilmeleri gerektiği düşünülmektedir. Araştırma konuları toplumun ihtiyaçlarına göre YÖK, MEB, üniversiteler ve çeşitli özel kuruluşların iş birliğiyle kararlaştırılmalıdır (Balcı, 2008). Çünkü yapılan çalışmaların nitelikli olmasının alanda yetiştirilen bilim insanlarının nitelikli olması ile doğru orantılı olduğu düşünülmektedir. Bu nedenle alanın epistemolojik, ontolojik temeline ve alandaki gelişmelere hakim bilim insanları tarafından yapılan çalışmalar alanın özgünleşmesine büyük katkı sağlayacaktır. Sadece akademik kaygı nedeniyle yapılan araştırmaların alanın ilerlemesi açısından sakıncalı olduğu düşünülmektedir. Nitekim Doğan ve Tok'un (2018) çalışmasında alanda yapılan çalışmaların çoğunun yardımcı doçent ünvanlı yazarlar tarafından yapıldığı belirtilmektedir. Bunun nedeni ise doçentlik sayısında yayın sayısının önemli olması şeklinde yorumlanmaktadır. Bu nedenle akademisyenlerin yükselme ve ilerleme konusunda kaygılarını azaltacak uygulamaların getirilmesinin yapılan çalışmaların niteliğine de yansıyacağı düşünülmektedir.

Sonuç olarak her toplumun kültürel, tarihi, politik, ekonomik, sosyolojik özellikleri birbirinden farklıdır. Bu özellikleri birbirinden farklı olan toplumların eğitim yönetimi alanında farklı sorunlara sahip olduğunu söylemek yanlış olmayacaktır. Eğitim yönetimi disiplin olarak gelişme göstermek amacındaysa, o zaman farklı yönetimsel 
problemler dizisi üzerine özgün sesler geliştirilmesi gerekliliği (Eacott, 2015) düşünüldüğünde alandaki çalışmaların, popüler konuların tekrarından ziyade toplumun kendine özgü ekonomik, siyasal, kültürel, toplumsal özellikleri ve sorunları dikkate alınarak bu sorunların çözümüne yönelik yürütülmesi gerekmektedir. 


\section{Kaynakça/References}

Balcı, A. (2008). Türkiye'de eğitim yönetiminin bilimleşme düzeyi. Kuram ve Uygulamada Eğitim Yönetimi Dergisi, 54, 181-209.

Balcı, A. ve Apaydın, Ç. (2009). Türkiye'de eğitim yönetimi araştırmalarının durumu: Kuram ve uygulamada eğitim yönetimi dergisi örneği. Kuram ve Uygulamada Eğitim Yönetimi Dergisi, 15(3), 325-344.

Bates, R. J. (1980). Educational administration, the sociology of science, and the management of knowledge. Educational Administration Quarterly, 16(2), 1-20.

Bates, R. J. (1982). Towards a Critical Practice of Educational Administration. İçinde T. J. Sergiovanni \& J. E. Corbally (Ed. ), Leadership anf organizational culture: New perspectiveson administrativet theory and practice. (pp. 260-275). University of Illinois Press.

Beycioğlu, K. ve Dönmez, B. (2006). Eğitim yönetiminde kuramsal bilginin üretimine ve uygulanmasına ilişkin bir değerlendirme. Kuram ve Uygulamada Ĕ̈itim Yönetimi, 47(47), 317-342.

Brundrett, M. (2001). The development of school leadership preparation programmes in England and the USA: A comparative analysis. Educational Management \& Administration, 29(2), 229-245.

Demirhan, G. (2015). Türkiye’de eğitim yönetimi alanında araştırma geleneği ve paradigmalarıngömülü teori bağlamında değerlendirilmesi. (Yayınlanmamış doktora tezi). Eskişehir Osmangazi Üniversitesi, Eskişehir.

Doğan, H. ve Tok, T. N. (2018). Türkiye'de eğitim bilimleri alanında yayınlanan makalelerin incelenmesi: Eğitim ve Bilim Dergisi örneği. Curr Res Educ, 4(2), 94-109.

Donmoyer, R. (2001). Evers and Lakomski's search for leadership's holy grail (and the intriguing ideas they encountered along the way). Journal of Educational Administration, 39(6), 554-572.

Eacott, S. (2015). The principalship, autonomy, and after. Journal of Educational Administration and History, 47(4), 414-431.

English, F. W. (2002). The point of scientificity, the fall of the epistemological dominos, and the end of the field of educational administration. Studies in Philosophy and Education, 21(2), 109-136.

Evers, C. W., \& Lakomski, G. (1996). Science in educational administration: A postpositivist conception. Educational Administration Quarterly, 32(3), 379-402.

Evers, C. W., \& Lakomski, G. (2001). Theory in educational administration: naturalistic directions. Journal of Educational Administration, 39(6), 499-520.

Greenfield, T. B. (1986). The decline and fall of science in educational administration. Interchange, 17(2), $57-$ 80 .

Griffiths, D. E. (1979). Intellectual turmoil in educational administration. Educational Administration Quarterly, $15(3), 43-65$

Gulbenkian Komisyonu Raporu. (2016). Sosyal bilimleri açın: Sosyal bilimlerin yeniden yapılanması üzerine rapor (Çev. Şirin Tekeli) (11. Basım). Metis Yayınları: İstanbul.

Gunter, H. M., \& Fitzgerald, T. (2008). Educational administration and history part 1: Debating the agenda. Journal Of Educational Administration and History, 40(1), 5-21.

Heck, R. H., \& Hallinger, P. (2005). The study of educational leadership and management: Where does the field stand today? Educational Management Administration \& Leadership, 33(2), 229-244.

Hyung, P. S. (2001). Epistemological underpinnings of theory developments in educational administration. Australian Journal of Education, 45(3), 237-248.

İşçi, S. (2013). Türkiye'de eğitim yönetimi alanında yapılmış lisansüstü tezlerin tematik, metodolojik ve istatistiksel açıdan incelenmesi. (Yayınlanmamış yüksek lisans tezi). Eskişehir Osmangazi Üniversitesi, Eskişehir.

Karaca, O. (2018). Türkiye'de eğitim yönetimi alanında yazılan lisansüstü tezlerin metodolojik incelemesi. (Yayınlanmamış yüksek lisans tezi). Uşak Üniversitesi, Uşak.

Karadağ, E. (2010). Eğitim bilimleri doktora tezlerinde kullanılan araştırma modelleri: Nitelik düzeyleri ve analitik hata tipleri. Kuram ve Uygulamada Eğitim Yönetimi, 1(1), 49-71. 
Karataş, İ. H., Kyzy, J. A. ve Topuz, C. (2015). Okul yöneticileri ile eğitim yönetimi alanında yapılan bilimsel araştırmalar ve çalışan bilim insanları arasındaki ilişki. Kuramsal Eğitimbilim Dergisi, 8(1), 125-152.

Kısa, N. (2016). Ĕ̆itim yönetimi alanındaki kuram-uygulama boşluğunun nedenleri ve çözüm önerileri. (Yayınlanmamış yüksek lisans tezi). Hacettepe Üniversitesi, Ankara.

Klein, J. T. (1993). Blurring, cracking, and crossing: Permeation and the fracturing of discipline. İçinde $\quad$ E. Messer-Davdow, D. D. Shumway \& D. Sylvan (Ed.), Knowledges: Historical and critical studies in disciplinarity. (pp. 185-214). London: University of Virginia Press.

Maxcy, S. J. (2001). Educational leadership and management of knowing: The aesthetics of coherentism. Journal of Educational Administration, 39(6), 573-588.

Oplatka, I. (2009). The field of educational administration: A historical overview of scholarly attempts to recognize epistemological identities, meanings and boundaries from the 1960s onwards. Journal of Educational Administration, 47(1), 8-35.

Oplatka, I. (2010). The legacy of educational administration: A historical analysis of an academic field. Frankfurt: Peter Lang.

Örücü, D. ve Şimşek, H. (2011). Akademisyenlerin gözünden Türkiye'de eğitim yönetiminin akademik durumu: Nitel bir analiz. Kuram ve Uygulamada Egitim Yönetimi Dergisi, 17(2), 167-197.

Özdemir, M. (2011). Kamu Yönetimi ve İşletme Yönetimi Arakesitinde Bir Bilim: Eğitim Yönetimi. Amme Idaresi Dergisi, 44 (2), 29-42.

Özdemir, M. (2017). Eğitim yönetiminde epistemik bunalımın arkeolojisi. Kuram ve Uygulamada Ĕ̈itim Yönetimi Dergisi, 23(2), 281-304.

Özdemir, M. (2018). Eğitim yönetimi: Alanın temelleri ve çă̆daş yönelimler. Anı Yayıncılık: Ankara.

Papa, R. (2009). The discipline of education administration: Crediting the past. http://citeseerx.ist.psu.edu/viewdoc/download?doi=10.1.1.512.7379\&rep=rep1\&type=pdf adresinden elde edildi.

Polat, G. (2010). Eğitim yönetimi ve denetimi anabilim dalında yapılmış lisansüstü tez çalışmalarının incelenmesi. (Yayınlanmamış yüksek lisans tezi). Maltepe Üniversitesi, İstanbul.

Riffel, J. A. (1978). The theory problem in educational administration. Journal of Educational Administration, 16(2), 139-149.

Sezgin, F., Kavgacı, H., ve Kılınç, A. Ç. (2011). Türkiye'de Eğitim Yönetimi ve Denetimi Lisansüstü Öğrencilerinin Öz Değerlendirmeleri. Yüksekögretim ve Bilim Dergisi, 1(3), 161-169.

Şişman, M. (1998). Eğitim yönetiminde kuram ve araştırmada alternatif paradigma ve yaklaşımlar. Kuram ve Uygulamada Ĕ̈itim Yönetimi, 16(16), 395-422.

Turan, S. (2004). Modernite ve postmodernite arasında bir insan bilimi olarak eğitim yönetimi. Akdeniz Üniversitesi Eğitim Fakültesi Dergisi, 1(1), 1-8.

Turan, S., ve Şişman, M. (2013). Eğitim yönetimi alanında üretilen bilimsel bilgi ve batılı biliş tarzının eleștirisine giriș. Kuram ve Uygulamada Ĕ̈itim Yönetimi, 19(4), 505-514.

Turan, S., Karadağ, E., Bektaş, F., ve Yalçın, M. (2014). Türkiye'de eğitim yönetiminde bilgi üretimi: Kuram ve Uygulamada Eğitim Yönetimi Dergisi 2003-2013 yayınlarının incelenmesi. Kuram ve Uygulamada Egitim Yönetimi Dergisi, 20(1), 93-119.

Türk Dil Kurumu Sözlüğü, (2018). Güncel Türkçe sözlük. http://www. gov.tr/index.php?option=com_bts\&arama=kelime_adresinden elde edildi.

Uysal, Ş. (2013). Türkiye’de eğitim yönetimi teftişi planlaması ve ekonomisi alanındaki doktora tezlerinin incelenmesi. (Yayınlanmamış doktora tezi). Eskişehir Osmangazi Üniversitesi, Eskişehir.

Yıldırım, Y. (2016). Eğitim yönetimi ve denetimi alanında yapılmış lisansüstü tez çalışmalarının liderlik teması açısından incelenmesi. (Yayınlanmamış yüksek lisans tezi). Aydın Üniversitesi, İstanbul.

Waite, D. (2002). The paradigm wars in educational administration: an attempt at transcendence. International Studies in Educational Administration, 30(1), 66-81.

Watkins, P. (1986). From managerialism to communicative competence: Control and consensus in educational administration. Journal of Educational Administration, 24(1), 86-106. 
Whitley, R. (2000). The intellectual and social organization of the sciences (2nd ed.). New York: Oxford University Press.

Willower, D. J. (1975). Theory in educational administration. Journal of Educational Administration, 13(1), $77-$ 91.

Willower, D. J., \& Forsyth, P. B. (1999). A brief history of scholarship on educational administration. Handbook of Research on Educational Administration, 2, 1-24. 